\title{
Molecular targeting of the Aurora-A/SMAD5 oncogenic axis restores chemosensitivity in human breast cancer cells
}

\author{
Mateusz Opyrchal ${ }^{5}$, Malgorzata Gil ${ }^{5}$, Jeffrey L. Salisbury ${ }^{2}$, Mathew P. Goetz ${ }^{1}$, \\ Vera Suman ${ }^{1}$, Amy Degnim¹, James McCubrey ${ }^{4}$, Tufia Haddad ${ }^{1}$, Ianko Iankov ${ }^{1}$, \\ Chenye B. Kurokawa ${ }^{3}$, Nicole Shumacher ${ }^{2}$, James N. Ingle ${ }^{1}$, Evanthia Galanis ${ }^{1,3}$ \\ and Antonino B. D'Assoro ${ }^{1,2}$ \\ ${ }^{1}$ Department of Medical Oncology, Mayo Clinic College Of Medicine, Rochester, MN, USA \\ ${ }^{2}$ Department of Biochemistry and Molecular Biology, Mayo Clinic College Of Medicine, Rochester, MN, USA \\ ${ }^{3}$ Department of Molecular Medicine, Mayo Clinic College Of Medicine, Rochester, MN, USA \\ ${ }^{4}$ Department of Microbiology and Immunology, East Carolina University, Greenville, NC, USA \\ ${ }^{5}$ Department of Medicine, Roswell Park Cancer Institute, Buffalo, NY, USA \\ Correspondence to: Antonino B. D'Assoro, email: Dassoro.antonio@mayo.edu \\ Keywords: breast cancer, chemoresistance, tumor progrression, EMT, stemness \\ Received: October 16, $2015 \quad$ Accepted: July 26, $2017 \quad$ Published: September 01, 2017
}

Copyright: Opyrchal et al. This is an open-access article distributed under the terms of the Creative Commons Attribution License 3.0 (CC BY 3.0), which permits unrestricted use, distribution, and reproduction in any medium, provided the original author and source are credited.

\section{ABSTRACT}

Although the majority of breast cancers initially respond to the cytotoxic effects of chemotherapeutic agents, most breast cancer patients experience tumor relapse and ultimately die because of drug resistance. Breast cancer cells undergoing epithelial to mesenchymal transition (EMT) acquire a CD44+/CD24// $\mathrm{ALDH1}^{+}$cancer stem cell-like phenotype characterized by an increased capacity for tumor self-renewal, intrinsic drug resistance and high proclivity to develop distant metastases. We uncovered in human breast tumor xenografts a novel non-mitotic role of Aurora-A kinase in promoting breast cancer metastases through activation of EMT and expansion of breast tumor initiating cells (BTICs). In this study we characterized the role of the Aurora-A/SMAD5 oncogenic axis in the induction of chemoresistance. Breast cancer cells overexpressing Aurora-A showed resistance to conventional chemotherapeutic agents, while treatment with alisertib, a selective Aurora-A kinase inhibitor, restored chemosensitivity. Significantly, SMAD5 expression was required to induce chemoresistance and maintain a breast cancer stem cell-like phenotype, indicating that the Aurora-A/SMAD5 oncogenic axis promotes chemoresistance through activation of stemness signaling. Taken together, these findings identified a novel mechanism of drug resistance through aberrant activation of the non-canonical Aurora-A/SMAD5 oncogenic axis in breast cancer.

\section{INTRODUCTION}

Tumor relapse associated with distant metastasis is a major cause of death for breast cancer patients [1]. The major hindrances in eradicating metastatic lesions include high tumor cell heterogeneity, self-renewal, and intrinsic resistance to chemotherapeutic agents [2,3]. While $70 \%$ of human breast carcinomas fall into luminal CD44\% $\mathrm{CD} 24^{+}$subtypes, which are estrogen receptor alpha (ERa) positive and are initially sensitive to endocrine therapy [4], triple negative breast carcinomas (TNBCs) show a basal- like $\mathrm{CD}_{4} 4^{+} / \mathrm{CD} 24-$ phenotype and low/absent levels of expression of ER $\alpha$, progesterone receptor (PR) and HER2 tyrosine kinase receptor [5]. ER $\alpha$ and HER2-targeted therapies are ineffective for TNBC [6]. Conventional chemotherapy is the only effective therapeutic option, and TNBCs generally respond well to cytotoxic agents in the earlier stages of the disease [7]. Unfortunately, metastatic ER+ and TNBCs will eventually exhibit resistance to anti-cancer drugs leading to tumor progression and poor outcomes [8-10]. Therefore, a better understanding of the molecular mechanisms responsible for drug resistance is 
imperative to accelerate the development of innovative strategies to restore chemosensitivity and improve the progression-free and overall survival of breast cancer patients.

Several studies have demonstrated that activation of epithelial to mesenchymal transition (EMT) reprogramming promotes drug resistance and tumor progression [11]. EMT is a key biological process observed in embryonic development, tissue regeneration and organ fibrosis during which cells progressively lose the epithelial features and gain mesenchymal properties [12]. Epithelial cancer cells can also activate EMT reprogramming that drives the progressive loss of adhesion molecules (E-cadherin and claudin) and concurrent increased expression of mesenchymal proteins (N-cadherin and vimentin) that favor cell motility and invasion [13-15]. Breast cancer cells that undergo EMT acquire a basallike $\mathrm{CD} 44^{+} / \mathrm{CD} 24^{-}$stemness phenotype characterized by a greater capacity for tumor self-renewal and early onset of distant metastasis [16-19]. The discovery that breast tumors contain a sub-population of cells with stemness properties, termed breast tumor initiating cells (BTICs), is critical to understanding the molecular mechanisms responsible for therapeutic failures and poor patient outcomes in advanced breast cancer [20, 21]. BTICs generally exhibit intrinsic resistance to conventional chemotherapy through different mechanisms that involve aberrant ABC transporter expression, increased ALDH1 activity, enhanced DNA repair activity to genotoxic stress and activation of self-renewal and survival pathways [22]. Breast tumors treated with conventional anti-cancer drugs may have residual drug-resistant BTICs, and it is these cells that promote tumor re-growth, metastatic dissemination and poor clinical outcomes.

EMT and stemness reprogramming are induced by several mechanisms: oncogenic pathways such as MAPK, Wnt, NOTCH, PI3K/AKT/mTOR and TGF $\beta /$ SMADs; components of the extracellular matrix such as collagen and hyaluronic acid; and hostile conditions such as hypoxia [23]. Prior studies have shown the Aurora-A mitotic kinase as a critical mediator of EMT and stemness in cancer cells $[24,25]$. In agreement with these findings, we have demonstrated in MCF-7 breast cancer xenografts engineered to express a constitutively active Raf-1 oncoprotein, the non-mitotic role of Aurora-A kinase in promoting distant metastasis through activation of EMT and development of CD44 $/$ CD24-BTICs [26]. Moreover, we have discovered the role of activated Aurora-A kinase in the induction of phosphorylation of the SMAD5 transcription factor that plays a critical role in orchestrating EMT and stemness reprogramming. Although the function of aberrant Aurora-A kinase activity in the development of cancer cell resistance to chemotherapeutic agents has been established [27-29], the underlying molecular mechanisms responsible for this have not been determined.

Here we define the role of the Aurora-A kinase in the induction of chemoresistance of breast cancer cells through phosphorylation and activation of SMAD5. We demonstrate that SMAD5 expression is required to induce a $\mathrm{CD} 44^{+} / \mathrm{CD} 24-/ \mathrm{ALDH}^{+}$breast cancer stem cell-like phenotype, suggesting that the Aurora-A/SMAD5 axis promotes chemoresistance through activation of stemness signalling in breast cancer. Taken together, these findings reveal a novel mechanism of drug resistance and provide the preclinical rationale to developstrategies that target the non-canonical Aurora-A/SMAD5 oncogenic axis and restore chemosensitivity in breast cancer cells.

\section{RESULTS}

\section{Raf-1-induced chemoresistance is not linked to loss of p53 function}

We have demonstrated that overexpression of a constitutive active Raf-1 mutant in ERa+ MCF-7 breast cancer cells $\left(\mathrm{vMCF}-7^{\Delta \mathrm{Rafl}}\right)$ resulted in constitutive activation of MAPK oncogenic signaling and enhanced tumorigenic properties in vivo $[26,30]$. Because aberrant activation of MAPK signaling is associated with chemoresistance [31], we investigated whether vMCF$7^{\Delta \text { Rafl }}$ cells exhibited resistance to daunorubicin (DR), a genotoxic stress-inducing agent [32]. Parental MCF7 and $v M C F-7^{\Delta \text { Rafl }}$ cells were treated with increased concentration of DR and relative cell proliferation was analyzed after 7 days. vMCF- $7^{\Delta \text { Rafl }}$ cells exhibited increased resistance to DR treatment when compared to $\mathrm{MCF}-7$ cells (Figure 1A). A clonogenic assay corroborated the increased resistance of vMCF-7 $7^{\triangle \mathrm{Raf} 1}$ cells to DR compared to parental MCF-7 cells (Figure 1B). The reduced chemosensitivity was also associated with lower levels of DR-induced genotoxic stress as confirmed by decreased histone $\mathrm{H} 2 \mathrm{AX}$ staining in $\mathrm{VMCF}-$ $7^{\Delta R a f 1}$ cells (Figure 1C). For the reason that resistance to genotoxic anti-cancer agents has been functionally linked to loss of p53 activity [33], we investigated whether Raf1 -induced chemoresistance was linked to impairment of p53 function. Expression of p53 and its downstream transcriptional target p21 was increased following DR treatment in both MCF-7 and vMCF-7 ${ }^{\Delta \text { Rafl }}$ cells (Figure 1D). These results demonstrate that $v M C F-7^{\triangle R a f 1}$ cells have an intact p53/p21 tumor suppressor axis and increased chemoresistance of vMCF-7 ${ }^{\Delta \text { Rafl }}$ cells is not linked to loss of p53 activity.

To determine the extent to which p21 expression was strictly dependent on p53 activity and not induced by Raf-1 signaling after genotoxic stress, we engineered vMCF-7 ${ }^{\triangle \mathrm{Raf} 1}$ cells to overexpress a dominant negative

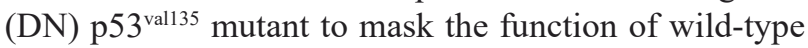
p53 (vMCF-7 $\left.7^{\Delta \operatorname{Rafl} / \mathrm{DNp} 53}\right)[32,34]$. Previous studies have shown that cancer cells with DNp53 val135 mutant also 
exhibit increased resistance to anti-cancer drugs [35]. vMCF-7 $7^{\triangle \mathrm{Raf} 1 / \mathrm{DNp} 53}$ cells showed low levels of p21 before and after genotoxic stress, indicating that p21 expression is dependent on wild-type p53 activity (Figure 1D). Because intact p53/p21 axis prevents onset of centrosome amplification after genotoxic stress [31], we determined the percentage of cancer cells harboring centriole overduplication following DR treatment. MCF-7 and vMCF- $7^{\Delta \text { Rafl }}$ cells showed lack of centriole overduplication following genotoxic stress, corroborating the integrity of p53/p21 axis in vMCF-7 ${ }^{\triangle R a f 1}$ cells (Supplementary Figure 1). Taken together, these findings demonstrate that Raf1 -induced chemoresistance does not require loss of p53 function in MCF-7 cells.

\section{Aurora-A kinase enhances Raf-1-induced chemoresistance}

We have previously demonstrated that ex-vivo vMCF-7 ${ }^{\Delta \text { Rafl }}$ cells (first generation xenografts, 1GX)

A

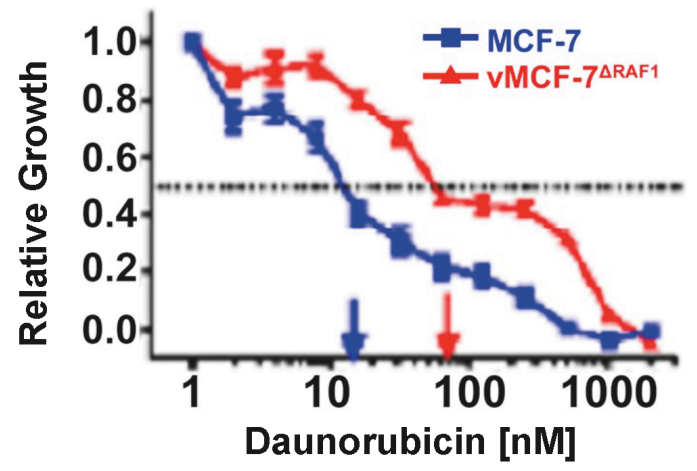

C

MCF-7

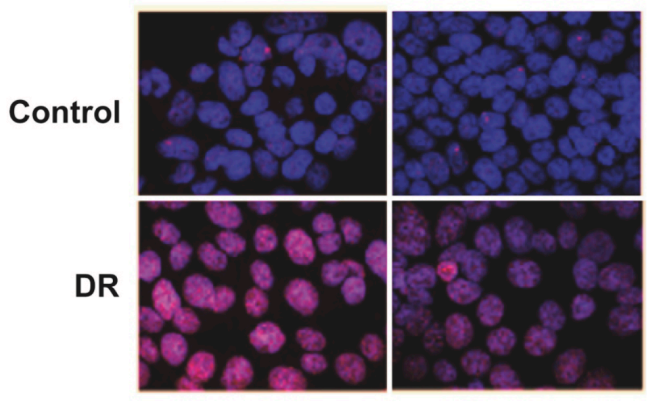

Histone H2AX staining established from metastatic vMCF-7 ${ }^{\triangle \mathrm{Rafl}}$ tumor xenografts, exhibited overexpression of Aurora-A mitotic kinase, while ex-vivo MCF-7 1GX cells established from nonmetastatic MCF-7 tumor xenografts (used as control) maintained nominal levels of Aurora-A [26]. Aurora-A overexpression in vMCF-7 $7^{\Delta \text { Rafl }} 1 \mathrm{GX}$ cells was functionally linked to EMT and the genesis of BTICs with a CD44 ${ }^{+}$ CD24 ${ }^{\text {Low/- }}$ basal-like phenotype [26]. Based on these findings, we investigated the role of Aurora-A kinase activity in enhancing Raf-1-induced chemoresistance. MCF-7, MCF-7 1GX, vMCF-7 ${ }^{\Delta R a f 1}$ and vMCF-7 ${ }^{\Delta R a f 1} 1 G X$ cells were treated with $\mathrm{DR}$ and cell viability was assessed after 7 days by MTT assay (Figure 2A). MCF-7 and MCF7 1GX cells showed sensitivity to DR treatment as both cell populations exhibited more than $60 \%$ decrease in cell proliferation after genotoxic stress. In contrast, vMCF$7^{\Delta \text { Rafl }}$ cells displayed $50 \%$ reduction in cell viability and vMCF-7 ${ }^{\Delta R a f 1} 1 \mathrm{GX}$ cells showed the highest resistance, i.e., $90 \%$, to DR. A clonogenic assay also corroborated the increased resistance of $v M C F-7^{\Delta R a f 1} 1 G X$ cells to

B

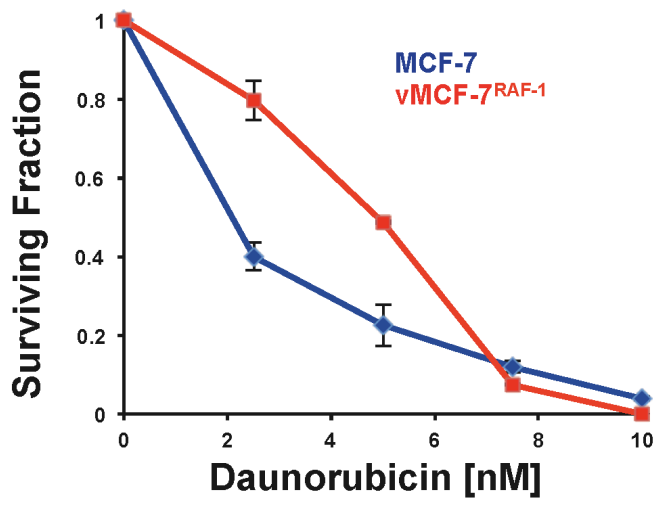

D

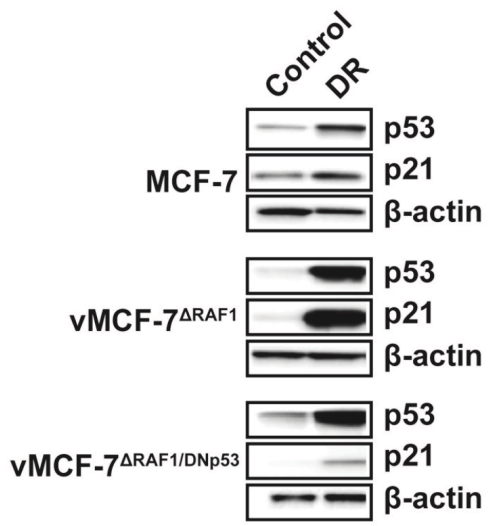

Figure 1: Development of Chemoresistance in Breast Cancer Cells. A. Cell Proliferation Assay showing that vMCF-7 ${ }^{\Delta R a f 1}$ cells exhibit higher resistance to escalating doses of DR compared to parental MCF-7 ${ }^{\text {ZZipNeo }}$ cells. B. Clonogenic assay showing that vMCF-7 ${ }^{\Delta R a f 1}$ cells are more resistant to DR compared to parental MCF-7pZipNeo cells. C. Immunofluorescence assay showing decreased histone H2AX staining in vMCF-7 ${ }^{\mathrm{Rafl}}$ cells compared to parental MCF-7 $7^{\text {pZipNeo }}$ cells following DR-induced genotoxic stress. Histone H2AX was labeled in red and nuclei were labeled in blue with Hoechst stain. D. Immunoblot assay showing expression of p53 and p21 before and following DR-induced genotoxic stress in MCF-7 ${ }^{\text {pZipNeo }}$, vMCF-7 ${ }^{\Delta \text { Rafl }}$ and vMCF-7 ${ }^{\triangle \mathrm{Rafl} / \mathrm{DNp} 53}$ cells. 
DR compared to parental MCF-7 and vMCF-7 ${ }^{\Delta R a f 1}$ cells (Supplementary Figure 2). Next, we established the extent to which high chemoresistance of vMCF-7 ${ }^{\Delta \text { Rafl }} 1 \mathrm{GX}$ cells was dependent on loss of p53 function that may have occurred during in vivo growth of vMCF-7 $7^{\Delta \text { Rafl }}$ cells. Following induction of genotoxic stress, vMCF-7 $7^{\Delta \text { Rafl }}$ 1GX cells exhibited increased expression of p53 and p21 in a similar fashion of parental cells (Figure 2B). These results demonstrate that high chemoresistance observed in vMCF-7 ${ }^{\triangle \mathrm{Raf} 1} 1 \mathrm{GX}$ cells is not linked to loss of $\mathrm{p} 53 / \mathrm{p} 21$ axis.

To establish whether deregulated expression of Aurora-A was linked to high chemoresistance, we analyzed Aurora-A levels before and after genotoxic stress in $v M C F-7^{\Delta R a f l} 1 G X$ and parental cells. Significantly, only vMCF-7 ${ }^{\Delta \text { Rafl }} 1 \mathrm{GX}$ cells didn't show down-regulation of Aurora-A after DR treatment (Figure 2B). Conversely, both vMCF-7 ${ }^{\Delta \text { Rafl }} 1 \mathrm{GX}$ and parental cells that received DR treatment exhibited down-regulation of another mitotic kinase, Polo-like kinase 1 (PLK1) that plays a central role in tumorigenesis (Figure 2B) [36]. A clonogenic assay showed that vMCF-7 $7^{\Delta \text { Rafl }} 1 \mathrm{GX}$ cells are more sensitive to alisertib (a selective Aurora-A kinase inhibitor) than parental vMCF-7 $7^{\Delta \text { Rafl }}$ cells (Figure $2 \mathrm{C}$ ), suggesting that vMCF- $7^{\Delta \text { Rafl }} 1 \mathrm{GX}$ cells are dependent on Aurora-A kinase activity for their growth and survival. Moreover, to assess the role of Aurora-A in enhancing chemoresistance, we performed a clonogenic assay using vMCF-7 ${ }^{\Delta \text { Rafl }}$ 1GX (with high endogenous levels of Aurora-A) and vMCF-7 ${ }^{\triangle R a f 1}$ cells engineered to overexpress Aurora-A (vMCF-7 $\left.{ }^{\Delta \text { Rafl/Aurora-A}}\right)$ as previously demonstrated [26]. Combination of DR with alisertib restored sensitivity to DR in vMCF-7 ${ }^{\triangle R a f 1} 1 G X$ and vMCF-7 ${ }^{\Delta \text { Rafl }}$ cells (Figure 2D), demonstrating that Aurora-A kinase activity is able to induce DR resistance.

Next, we performed a MTT assay to validate the role of Aurora-A kinase in inducing resistance to DR and paclitaxel (PTX), a conventional chemotherapeutic agent
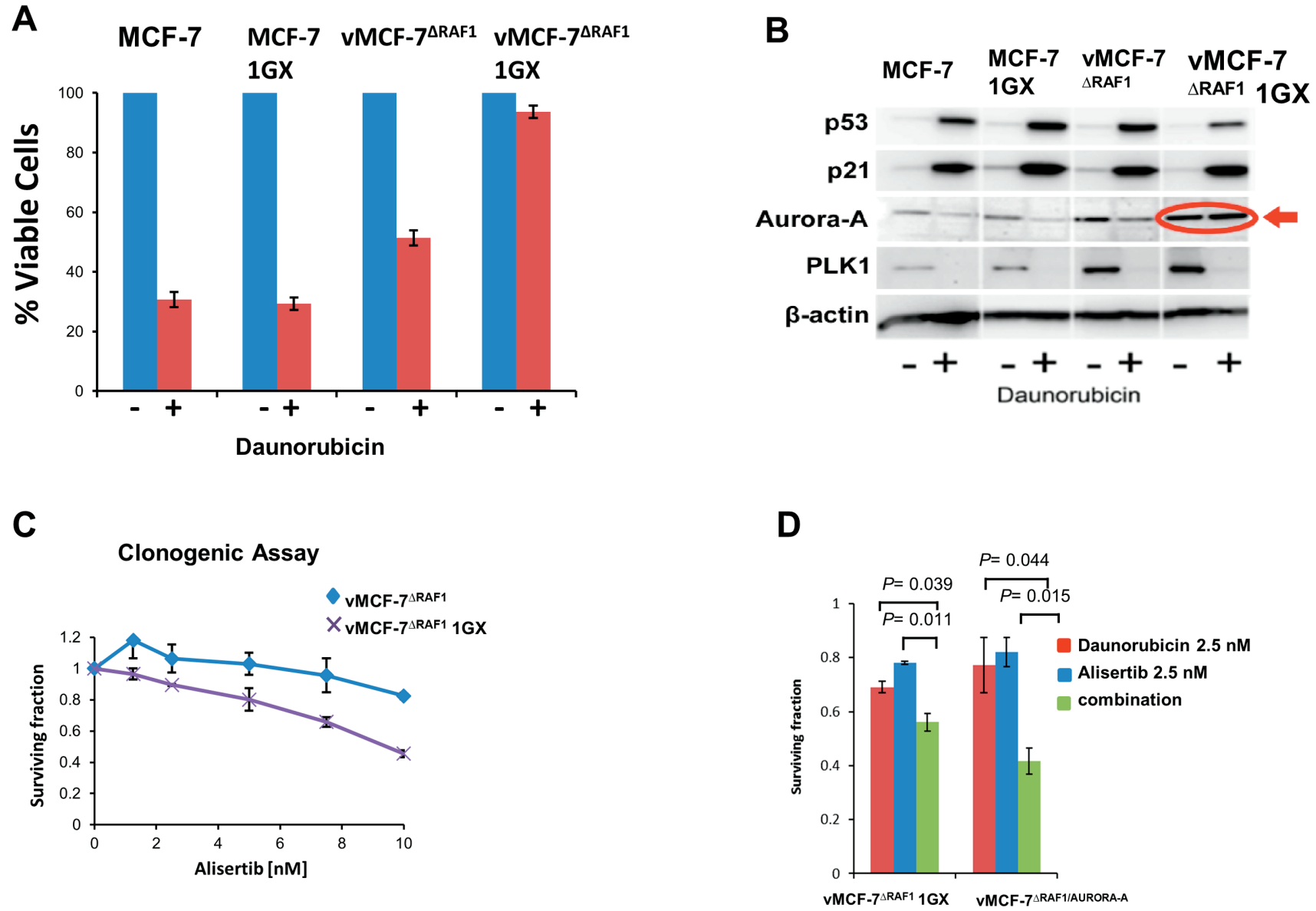

Figure 2: Aurora-A Kinase Activity is Required to Induce Chemoresistance. A. MTT assay showing that vMCF-7 $7^{\triangle R a f l} 1 \mathrm{GX}$ cells display the highest resistance to DR compared to parental cells. Graph represents the average from three independent experiments. B. Immunoblot assay showing expression of p53, p21, Aurora-A and PLK1 before and after DR-induced genotoxic stress in variant and parental MCF-7 cells. C. Clonogenic assay showing that treatment with the Aurora-A kinase inhibitor alisertib reduces the survival of vMCF-7 ${ }^{\Delta R a f l}$ and vMCF-7 $7^{\Delta R a f l} 1 G X$ cells. D. Clonogenic assay showing that treatment with alisertib restores sensitivity to DR in vMCF$7^{\Delta \text { Rafl }} 1 \mathrm{GX}$ and vMCF-7 $7^{\Delta \text { Rafl/Aurora-A }}$ cells. Results are presented as the average of three independent experiments $\pm S E M$. 
that stabilizes microtubules and triggers mitotic arrest and apoptosis [37]. vMCF-7 $7^{\Delta \text { Rafl }} 1 \mathrm{GX}$ and vMCF-7 $7^{\Delta \mathrm{Raf} 1 /}$ Aurora-A cells were treated with $1 / 2$ IC50 alisertib alone and in combination with $1 / 2$ IC50 DR or $1 / 2$ IC50 PTX (Figure 3). IC50s for alisertib, DR and PTX were previously established (Supplementary Figure 3). Treatment of vMCF-7 $7^{\triangle \mathrm{Rafl}} 1 \mathrm{GX}$ and vMCF-7 ${ }^{\triangle \mathrm{Rafl}}$ cells with DR or PXT in combination with alisertib restored chemosensitivity (Figure 3A-3D). Taken together, these results demonstrate that inhibition of Aurora-A kinase activity restores sensitivity to conventional chemotherapeutic agents in drug-resistant breast cancer cells.

\section{Pharmacological inhibition of Aurora-A kinase activity reduces phosphorylated SMAD5 and restores chemosensitivity}

To corroborate the role of Aurora-A in enhancing chemoresistance in TNBC, we employed the highly metastatic MDA-MB 231 cell line [38]. MDA-MB 231 cells showed a basal-like CD $44^{+} / \mathrm{CD} 24^{-}$phenotype that was linked to high endogenous levels of phosphorylated Aurora-A ( $p \sim$ Aurora-A) compared to MCF-7 cells that exhibited a luminal CD44-CD24+ phenotype and nominal levels of $\mathrm{p} \sim$ Aurora-A (Figure $4 \mathrm{~A}$ and $4 \mathrm{~B}$ ). These results are in agreement with our previous findings demonstrating that overexpression of $\mathrm{p} \sim$ Aurora- $A$ is restricted to the basal-like $\mathrm{CD} 44^{+} / \mathrm{CD} 24^{-}$sub-fraction in breast tumors [26]. Therefore, we investigated the role of Aurora-A kinase activity in promoting resistance to doxorubicin (an antracycline with comparable activity of daunorubicin that is used in TNBC treatment) and PTX. Treatment of MDA-MB 231 cells with $1 / 2$ IC50 doxorubicin or $1 / 2$ IC50 PXT had nominal effects on cell viability (Figure 4C). Significantly, when MDA-MB 231 cells were treated with $1 / 2$ IC50 Alisertib in combination with the same concentration of the chemotherapeutic agent, we observed a significant decrease in cellular proliferation compared to cells treated with doxorubicin or PTX alone (Figure 4C). IC50s for alisertib, DR and PTX in MDA-MB 231 cells

B

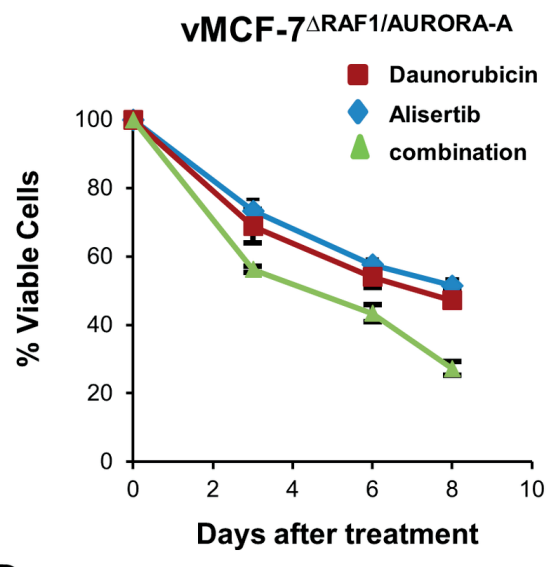

D

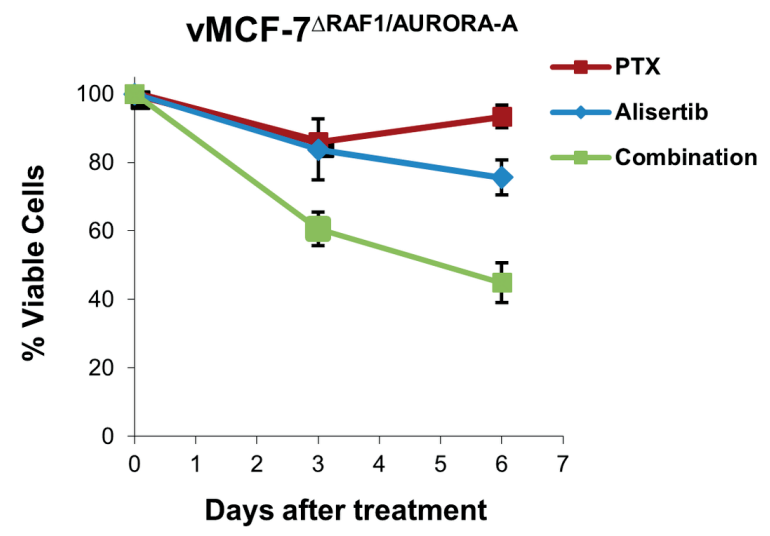

Figure 3: Aurora-A-Targeted Therapy Restores Chemosensitivity. A.-D. MTT assay showing that treatment with the Aurora-A kinase inhibitor alisertib restores sensitivity to DR and PTX in vMCF-7 ${ }^{\triangle \text { Rafl }} 1 \mathrm{GX}$ and vMCF-7 ${ }^{\triangle \text { Rafl/Aurora-A }}$ cells. Results are presented as the average of three independent experiments \pm SEM. 
had been previously established (Supplementary Figure 4).

Since we previously demonstrated that Aurora-A kinase activity is required to induce nuclear phosphorylation and activation of SMAD5 transcription factor in vMCF-7 ${ }^{\Delta \text { Rafl }}$ cells $[26,39]$, we assessed the role of Aurora-A kinase activity in inducing SMAD5 phosphorylation in MDA-MB 231 cells. Inhibition of Aurora-A phosphorylation was associated with reduced $\mathrm{p} \sim \mathrm{SMAD}$, corroborating the role of Aurora-A kinase activity in promoting SMAD5 phosphorylation (Figure 4D). Taken together, these findings validate, in TNBC cells, the critical role of Aurora-A kinase activity in inducing chemoresistance. Likewise, they also suggest that aberrant Aurora-A kinase activity may favor a chemoresistant phenotype through activation of SMAD5.

\section{SMAD5 expression is required to induce chemoresistance}

To explore the function of SMAD5 in inducing chemoresistance, we employed SMAD5 specific siRNAs to knockdown SMAD5 expression in MDA-MB 231 cells (Figure 5A). Because treatment with PTX induces G2/M cell cycle arrest in chemosensitive cancer cells [40], MDA-MB 231 cells were treated with PTX and/or siRNAs targeting SMAD5 (Scramble siRNAs were used as control) and cell cycle profile was analyzed by FACS assay. While treatment with PTX did not induce G2/M cell cycle arrest, treatment with PTX and siRNA-SMAD5 resulted in G2/M cell cycle arrest, indicating that siRNA-SMAD5 restored PTX anti-mitotic activity (Figure 5B). Because PTXinduced cell cycle arrest is functionally linked to activation of apoptosis [40], we tested the levels of cleaved-PARP (a
A

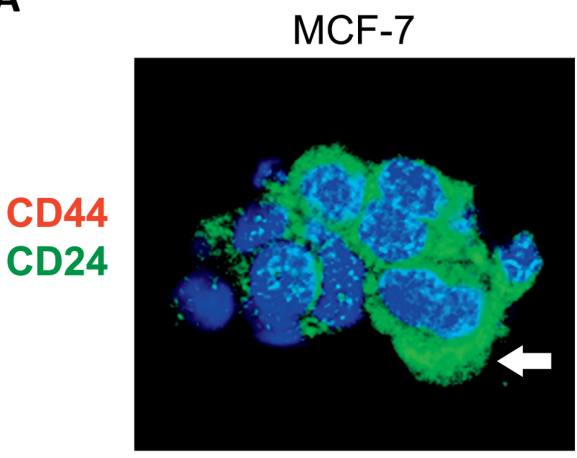

CD44+/CD24-: $4 \%$

C

MDA-MB 231

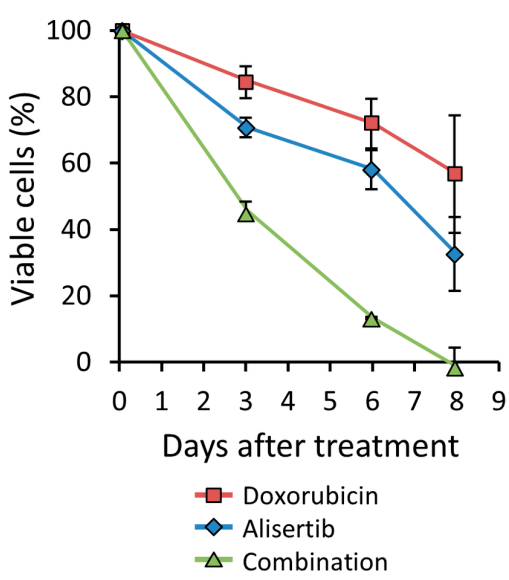

MDA-MB 231

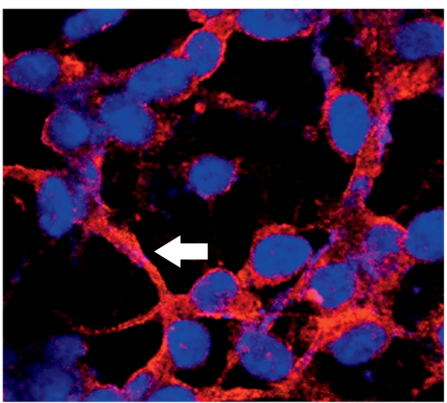

CD44+/CD24-: 93\%

B

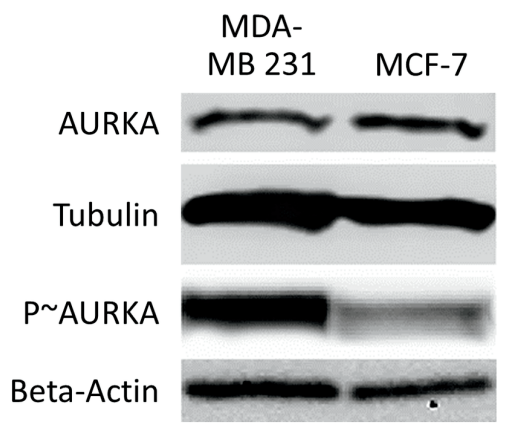

D

MDA-MB 231

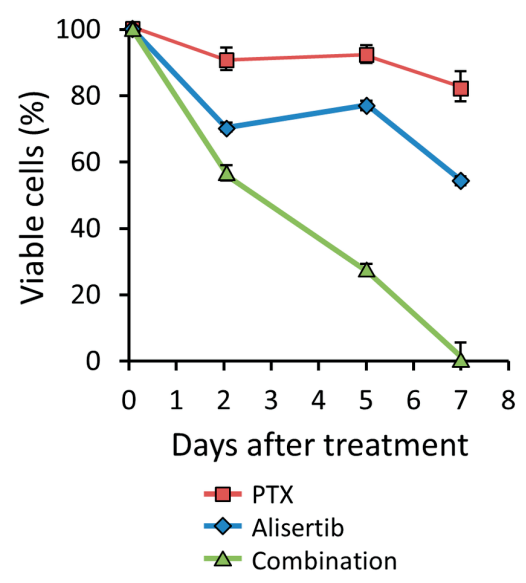

MDA-MB 231

NIA Immunoassay

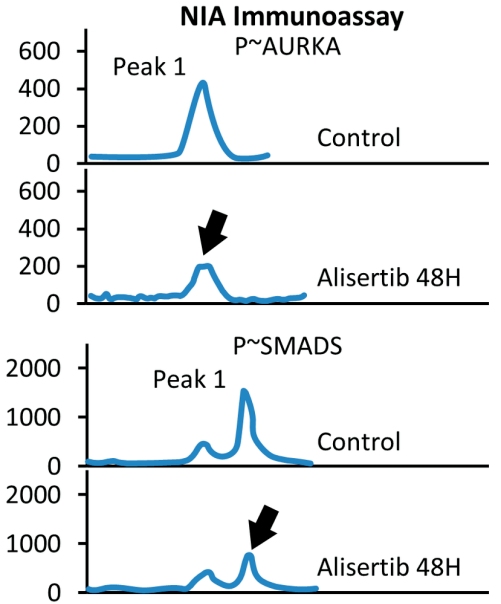

Figure 4: Pharmacologic Targeting of Aurora-A Restores Chemosensitivity. A. Immunofluorescence analysis showing the percentage of $\mathrm{CD}_{4} 4^{+} \mathrm{CD} 24^{-}$sub-fraction in MCF-7 and MDA-MB 231 breast cancer cells. B. Immunoblot assay showing the expression of total and phosphorylated (p ) Aurora-A in MDA-MB 231 and MCF-7 cells. Tubulin and Beta-actin expression were used as loading control. C. MTT assay showing that treatment with alisertib restores sensitivity to Doxorubicin and PTX in MDA-MB 231 cells. Results are presented as the average of three independent experiments \pm SEM. D. Highly sensitive NIA immunoassay showing a decrease in Aurora-A and SMAD5 phosphorylation after treatment with alisertib in MDA-MB 231 Cells. Results are derived from three independent experiments with comparable outcomes. 
marker of apoptosis) in MDA-MB 231 cells treated with PTX and/or siRNA-SMAD5 (Scramble siRNAs were used as control). Increased expression of cleaved-PARP was observed only in cells treated with PTX and siRNASMAD5 (Figure 5C). Next, we performed a MTT assay to explore the role of SMAD5 expression in inducing chemoresistance. MDA-MB 231 cells were treated with siRNA-SMAD5 alone and in combination with $1 / 2$ IC50 doxorubicin or $1 / 2$ IC50 PTX. Treatment of MDA-MB 231 cells with doxorubicin or PXT in combination with siRNA-SMAD5 restored chemosensitivity (Figure 5D). Combination of siRNA-SMAD5 with $1 / 2$ IC50 doxorubicin or $1 / 2$ IC50 PTX also restored chemosensitivity in BT549 TNBC cells (Supplementary Figure 5). Taken together, these results demonstrate that SMAD5 expression is required to induce chemoresistance in TNBC cells that exhibit high endogenous Aurora-A kinase activity.

\section{SMAD5-induced chemoresistance is linked to maintenance of a $\mathrm{CD}^{+} / \mathrm{CD}^{-} / \mathrm{PROCR}^{+}$cancer stem-like Phenotype}

Because expression of the CD44 stemness marker promotes chemoresistance in breast cancer cells [41], we investigated the extent to which SMAD5 activity was required to induce CD44 expression in MDA-MB 231 cells. Following treatment of MDA-MB 231 cells with siRNA-control or siRNA-SMAD5, CD44 expression was markedly reduced only in MDA-MB 231 cells treated with siRNA-SMAD5 (Figure 6A). Moreover, treatment with siRNA-SMAD5 induced a luminal CD44-/CD24 phenotype in MDA-MB 231 cells (Figure 6B), indicating that SMAD5 expression is required to maintain a $\mathrm{CD}_{4}{ }^{+} /$ CD24- cancer stem cell-like phenotype. Although CD44 and CD24 are well-established markers of breast cancer stemness, they are not universal surface markers for the definitive characterization of a breast cancer stem-
A

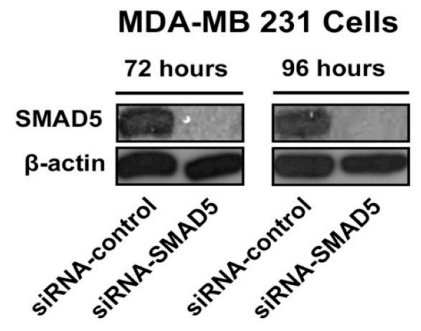

C

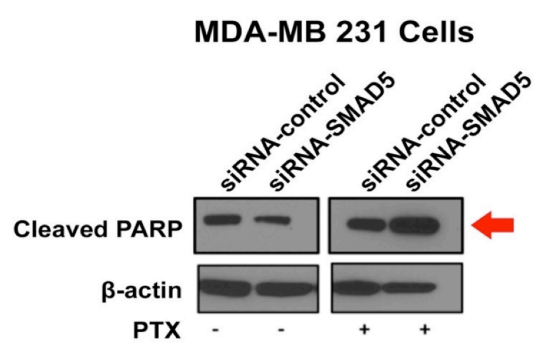

B

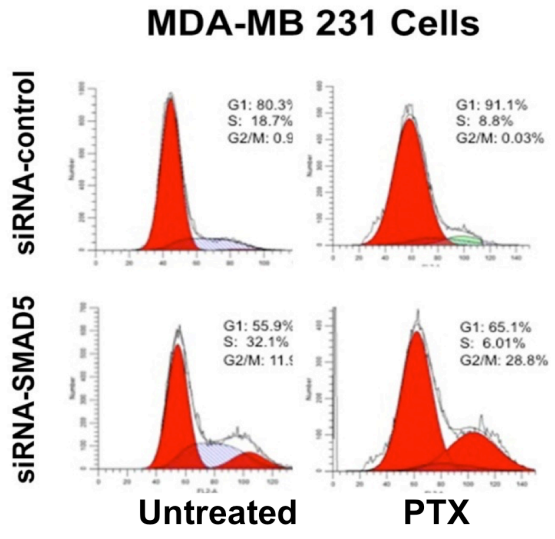

MDA-MB 231
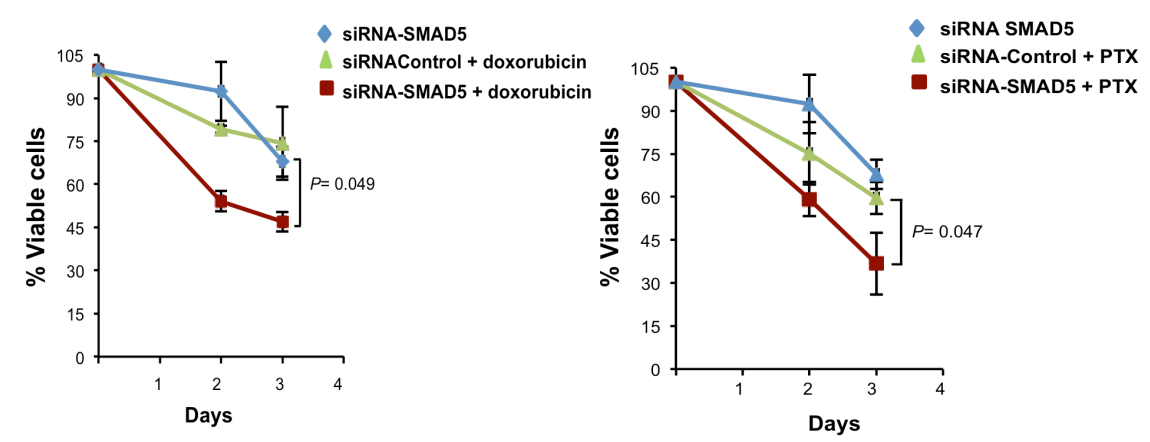

Figure 5: SMAD5 Expression is Required to Induce Chemoresistance. A. Immunoblot assay showing reduced SMAD5 expression in MDA-MB 231 cells after treatment with siRNA-SMAD5 for 72 and 96 hours. B. FACS analysis showing that treatment with siRNA-SMAD5 for 96 hours restores PTX-induced G2/M phase arrest in MDA-MB 231 cells. Scramble siRNAs were used as control. Results are derived from three independent experiments with comparable outcomes. C. Immunoblot assay showing expression of cleavedPARP in MDA-MB 231 cells treated for 96 hours with PTX and/or siRNA-SMAD5. Scramble siRNAs were used as control. D. MTT assay showing that treatment with siRNA-SMAD5 restores sensitivity to Doxorubicin and PTX in MDA-MB 231 cells. Scramble siRNA were used as control. Results are presented as the average of three independent experiments $\pm S E M$. 
like phenotype. For this reason, we also investigated the expression of PROCR, a well-established breast cancer stemness marker linked to higher tumorigenicity [16]. The majority of MDA-MB 231 cells treated with siRNA-control were positive for PROCR staining, while MDA-MB 231 cells treated with siRNA-SMAD5 showed a marked decrease of PROCR expression (Figure 6C). Finally, to determine the extent to which SMAD5 expression was required to induce ALDH1 activity that is responsible for stemness capacity and high chemoresistance, we performed an Aldeofluor assay in MDA-MB 231 cells treated with siRNA-control or siRNASMAD5. ALDH1 activity was significantly reduced in MDA-MB 231 cells treated with siRNA-SMAD5 (Figure $6 \mathrm{D})$, corroborating the findings that SMAD5 expression is required to promote tumor stemness and chemoresistance.

A

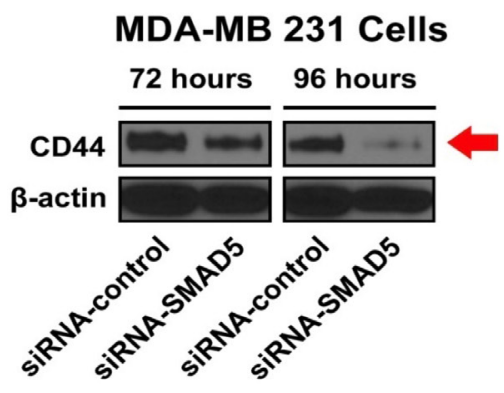

C

MDA-MB 231

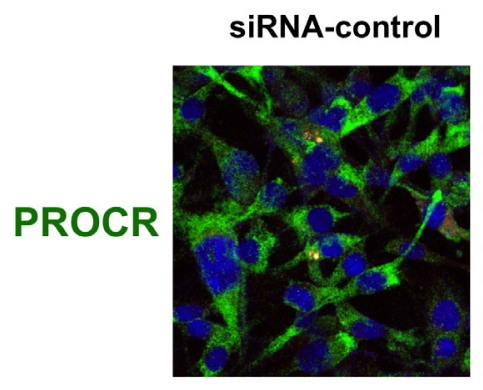

PROCR+: $62 \%$
SIRNA-SMAD5

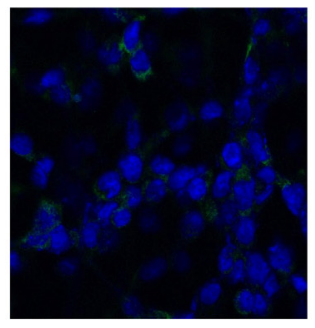

PROCR+: $7 \%$
B

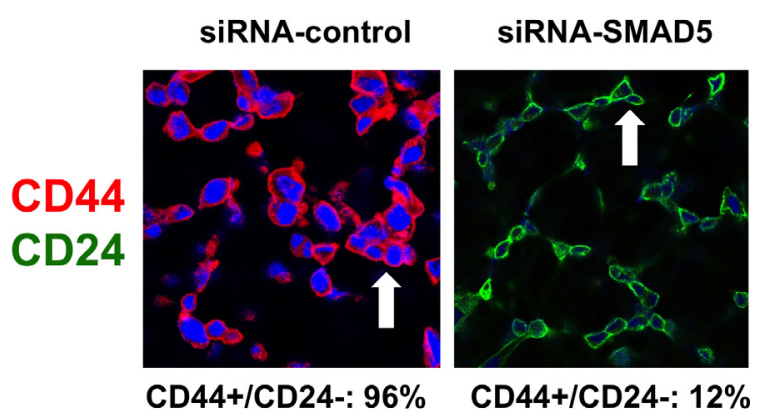

MDA-MB 231
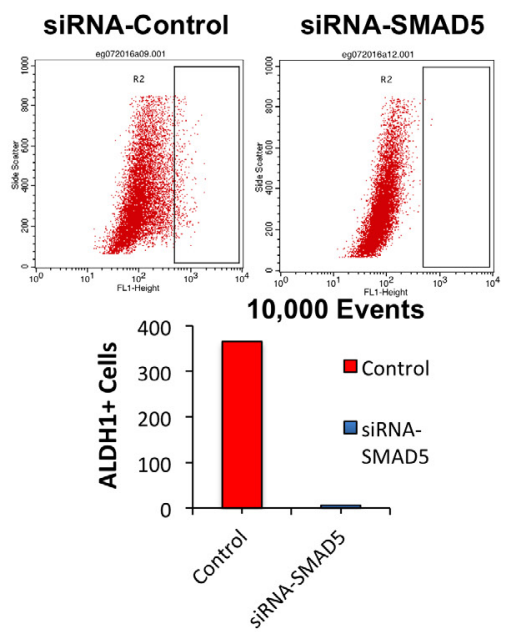

Figure 6: A. Immunoblot assay showing the expression of CD44 stemness marker after treatment with siRNA-SMAD5 for 72 and 96 hours in MDA-MB 231 cells. Scramble siRNA were used as control. B. Immunofluorescence assay showing the percentage of $\mathrm{CD}_{4}{ }^{+} /$ CD24- sub-fraction in MDA-MB 231 cells before and after treatment with siRNA-SMAD5 for 96 hours. Scramble siRNA were used as control. C. Immunofluorescence assay showing the percentage of PROCR ${ }^{+}$MDA-MB 231 cells before and after treatment with siRNASMAD5 for 96 hours. Scramble siRNA were used as control. D. FACS showing ALDH1 activity in MDA-MB 231 cells before and after treatment with siRNA-SMAD5 for 96 hours. Scramble siRNA were used as control. Graph showing the number of ALDH1+ cells (average from three independent experiments) in MDA-MB 231 cells before and after treatment with siRNA-SMAD5 for 96 hours. Scramble siRNA were used as control. Experiments were performed in triplicate with comparable results. 
In this study, we defined the role of the Aurora-A/SMAD5 oncogenic axis in the induction of chemoresistance in breast cancer cells. First, we employed luminal ER+ MCF-7 cells with constitutively active Raf/MAPK signaling (vMCF-7 ${ }^{\triangle \mathrm{Raf} 1}$ ) that exhibit a more aggressive phenotype than parental cells [26]. vMCF-7 ${ }^{\Delta \mathrm{Raf} 1}$ cells showed higher resistance to the genotoxic agent DR compared to MCF-7 cells, corroborating the causal role of Raf/MAPK oncogenic signaling in promoting resistance to conventional anti-cancer drugs [46]. Although it has been showed that Raf/MAPK signaling induces expression of multi-drug resistant P-glycoprotein [47], the molecular mechanisms responsible for Raf/MAPK-mediated drug resistance are poorly characterized. Because impaired p53 function is linked to chemoresistance in cancer cells [48], we investigated whether constitutive activation of Raf/MAPK signaling reduced the expression of p53 and its downstream target p21 after genotoxic stress. Significantly, Raf/MAPK-driven chemoresistance was not linked to loss of integrity of p53/p21 tumor suppressor axis, suggesting that Raf/MAPK oncogenic signaling induces drug resistance through p53-independent mechanisms in MCF-7 cells.

Since we have established a novel oncogenic cross- talk between Raf/MAPK signaling and Aurora-A kinase in the activation of EMT and breast cancer progression [26], we aimed to determine the role of Aurora-A in promoting Raf/MAPK-induced chemoresistance. High endogenous levels of Aurora-A in ex-vivo vMCF-7 ${ }^{\Delta \text { Rafl }} 1 \mathrm{GX}$ cells were linked to resistance to conventional chemotherapeutic agents. Moreover, Aurora-A expression levels remained high after DR-induced genotoxic stress in vMCF-7 ${ }^{\Delta \text { Rafl }}$ 1GX cells that exhibited the highest resistance to DR compared to parental cells regardless the presence of an intact p53/p21 axis. Significantly, pharmacologic targeting of Aurora-A kinase activity with alisertib restored chemosensitivity, demonstrating that Aurora-A activity is required to promote Raf/MAPK-induced chemoresistance in ER+ breast cancer cells. Although one of the mechanisms by which Aurora-A induces oncogenic transformation is through down-regulation of p53 activity [49], our findings demonstrate that Aurora-A-induced resistance to genotoxic agents does not require abrogation of p53 function. One of the alternative molecular mechanisms by which aberrant Aurora-A kinase activity may induce chemoresistance in cancer cells is likely through activation of EMT and stemness reprogramming. In agreement with this hypothesis, we have demonstrated

\section{Aurora-AISMAD5 Oncogenic Axis}

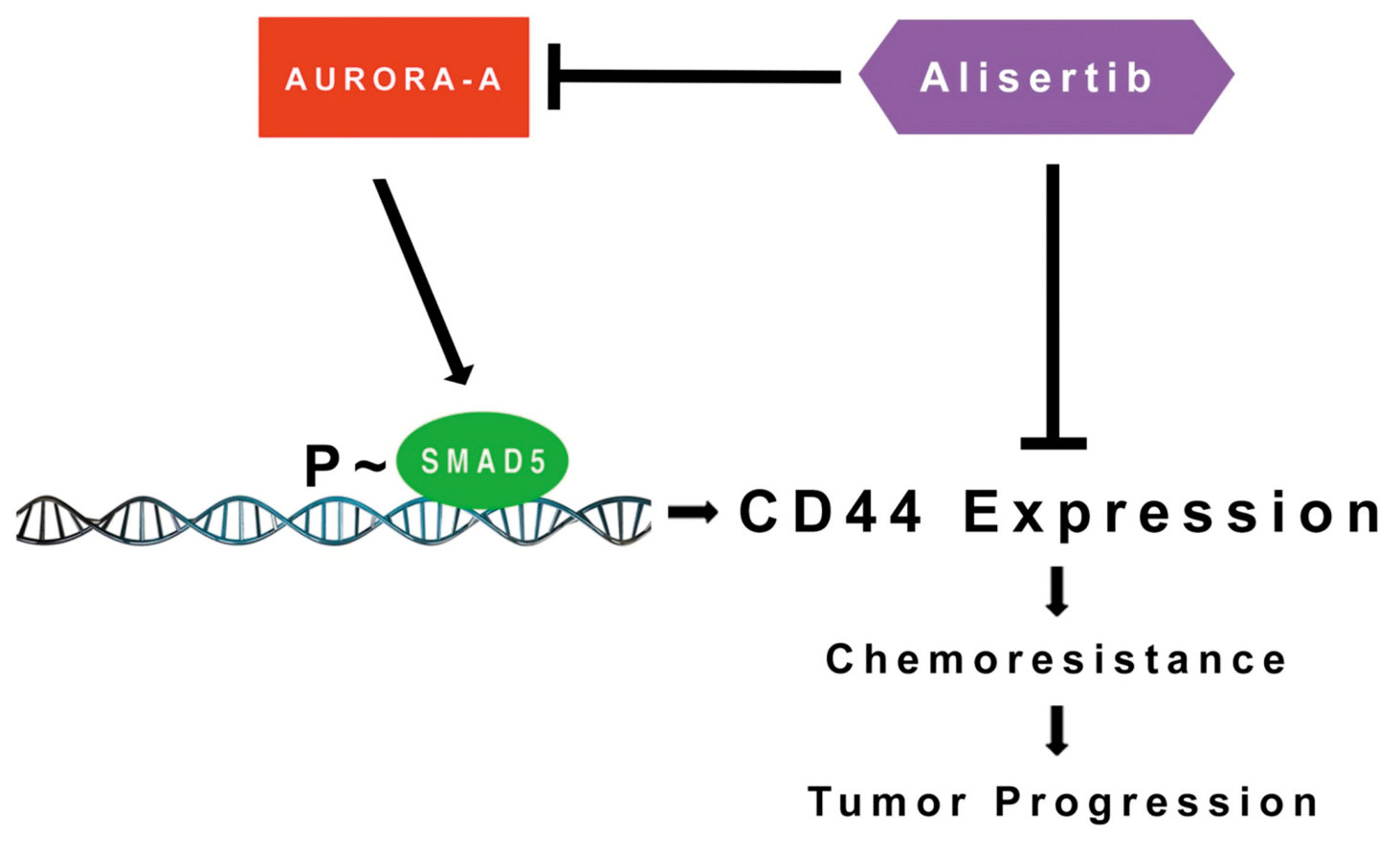

Figure 7: Molecular Targeting of the Aurora-A/SMAD5 Oncogenic Axis Restores Chemosensitivity: Aberrant Aurora-A kinase activity induces phosphorylation of SMAD5 transcriptional factor that in turn will promote expression of CD44 receptor and activation of stemness signaling responsible for chemoresistance and tumor progression. Pharmacologic targeting of Aurora-A kinase activity can be effective to restore chemosensitivity through inhibition of the Aurora-A/SMAD5 oncogenic axis and stemness signalings in cancer cells. 
the causative role of Aurora-A in promoting the expansion of $\mathrm{CD}_{4} 4^{+} / \mathrm{CD} 24^{-} / \mathrm{ER}^{-}$BTICs responsible for the onset of distant metastases in vMCF-7 ${ }^{\Delta \text { Rafl }}$ tumor xenografts [26]. To corroborate the function of Aurora-A in promoting Raf/ MAPK-induced chemoresistance, we employed highly metastatic MDA-MB 231 TNBC cells with elevated endogenous Raf/MAPK activity [50]. MDA-MB 231 cells showed a basal-like $\mathrm{CD} 44^{+} / \mathrm{CD} 24^{-}$phenotype that was linked to high levels of $\mathrm{p} \sim$ Aurora-A and resistance to doxorubicin and PTX. Following treatment with alisertib, MDA-MB 231 cells gained sensitivity to chemotherapeutic agents, demonstrating the role of Aurora-A kinase activity in inducing chemoresistance also in TNBC cells. In agreement with our previous results [26], Aurora-Ainduced drug resistance was linked to phosphorylation of SMAD5, a key transcription factor downstream of TGF-b/ BMP signaling involved in tumor progression $[51,52]$. Significantly, molecular targeting of SMAD5 expression was linked to inhibition of a CD $44^{+} / \mathrm{CD} 24 / \mathrm{PROCR}^{+}$ cancer stem cell-like phenotype and low ALDH1 activity. Taken together, these findings demonstrate that SMAD5 expression is required to induce chemoresistance through maintenance of tumor stemness in TNBC cells.

In conclusion, the study presented here proposes a novel mechanism of breast cancer progression by which aberrant activation of the Aurora-A/SMAD5 oncogenic axis induces expression of CD44 and PROCR receptors and increased ALDH1 activity that are critical to maintain a cancer stem cell-like phenotype responsible for chemoresistance and tumor progression (Figure 7). Conversely, pharmacologic targeting of Aurora-A restores chemosensitivity through inhibition of SMAD5 transcriptional activity leading to restoration of a more differentiated luminal CD44-/CD24+/PROCR phenotype with low ALDH1 activity and impairment of tumor stemness. The combination of conventional chemotherapeutic drugs with inhibitors of Aurora-A kinase activity represents a promising therapeutic strategy for the management of chemoresistant breast cancer, particularly TNBCs that currently lack FDA-approved targeted therapies.

\section{MATERIALS AND METHODS}

\section{Human breast cancer cell lines}

The human breast cancer cell lines MCF-7 and MDA-MB 231 were obtained from ATCC (Manassas, Virginia, USA). Variant MCF-7 expressing the constitutive active Raf-1 and DN p53 $3^{\text {val135 }}$ mutants, vMCF-7 ${ }^{\Delta \text { Rafl }} 1 \mathrm{GX}$ and MCF-7 1GX cells were generated as previously described [26, 32, 34]. All cell lines were maintained in DMEM medium containing $5 \mathrm{mM}$ glutamine, $1 \%$ penicillin/streptomycin and $10 \% \mathrm{FBS}$ at $37 \mathrm{C}$ in $5 \% \mathrm{CO} 2$ atmosphere.

\section{Cell proliferation assay}

Cancer cells were seeded in 96-well plates at a density of 100 cells/well in the absence or presence of escalating doses of DR. After 7 days incubation, cells were recovered with trypsin/EDTA (Life Technologies, Inc.), stained with trypan blue and counted with a hemacytometer. Experiments were performed in quadruplicate and $\pm S E M$ was calculated.

\section{Clonogenic assay}

Cells were plated in duplicates on 6 well plates with densities varying from 50 to 200 cells/well. The cells were treated with daunorubicin, paclitaxel or alisertib at indicated concentrations and cultured in a $37^{\circ} \mathrm{C}, 5 \%$ $\mathrm{CO}_{2}$ incubator for 12 days. The media were replaced every 3 days. The cells were fixed with methanol/acetic acid $(7: 1)$ and stained with $0.5 \%$ crystal violet in methanol for $60 \mathrm{~min}$. Individual colonies of more than 50 cells were counted. The survival fraction was calculated as follows: Surviving fraction $=$ colonies counted $/($ cells seeded $\times \mathrm{PE})$ $\mathrm{x} 100)$ where $\mathrm{PE}$ is the plating efficiency that represents the ratio of the number of colonies to the number of cells seeded.

\section{Immunoblot, immunofluorescence and FACS assays}

Immunoblot, Immunofluorescence and FACS assays were performed as previously described [26]. Antibodies employed to perform these studies were the followings: p53 (D07 DAKO), p21 (Oncogene), Centrin 20h5 (Mayo Clinic, Rochester, Minnesota, USA), H2AX, Aurora-A, $\mathrm{p} \sim$ Aurora-A, SMAD5, PLK1, cleaved-PARP, CD44 (Cell Signaling, Danvers, Massachusetts, USA), CD44, CD24 (BD Pharmigen, San Jose, California, USA), PROCR and Beta-actin (Sigma, St. Louis, Missouri, USA). Results are derived from three independent experiments with comparable outcomes.

\section{Nano-fluidic immunoassay (NIA)}

Lysates were analyzed using a NanoPro 1000 system (ProteinSimple Inc.) with an optimized protocol. Primary antibodies were used at 1:50 dilution for 2 hours. Antibodies employed to perform the NIA assay were the followings: p Aurora-A (Cell Signaling, Danvers, Massachusetts, USA) and p SMAD5 (Abcam, Cambridge, Massachusetts, USA). Results are derived from three independent experiments with comparable outcomes. 


\section{Chemoresistance studies}

Cell viability was determined employing the MTT [3-(4, 5-dimethylthiazol-2-yl)-2, 5-diphenyltetrazolium] colorimetric assay (ATCC, Manassas, Virginia, USA). Cancer Cells were plated at a density of $10^{4}$ cells/well in 96-well plates. Twenty-four hours after seeding, the cells were treated with paclitaxel and/or alisertib. Cell viability assay was performed at indicated time points after treatment initiation following the manufacturer's instructions. Briefly, cells were incubated with $10 \%$ cell proliferation kit I added directly to the medium for 4 hours at $37^{\circ} \mathrm{C}$, followed by cell lysis with a detergent reagent (ATCC) overnight in the dark at room temperature. Absorbance was determined in a SpectraMax microplate reader (Molecular Devices, Sunnyvale, CA) at $570 \mathrm{~nm}$ in three to six different wells per group and results were calculated as the percent of optical density in the treated wells versus the untreated (used as control). Results are presented as the means of three independent experiments \pm SEM.

\section{RNA interference assay}

The siGENOME Human SMAD5 siRNAs and siGENOME Non-targeting siRNA (Thermo Scientific, West Palm Beach, Florida, USA) were transfected into the breast cancer cells at the final concentration $25 \mathrm{nM}$ using DharmaFECT 1 Transfection Agent (Thermo Scientific) according to the manufacturer's instructions. The siRNAtreated cells were collected after 72 and 96 hours and lysed with cell lysis buffer (Cell Signaling, Danvers, Massachusetts, USA) to assess SMAD5 expression.

\section{Cell cycle analysis}

Trypsinized and floating cells were pooled, washed with PBS-EDTA, and fixed in 70\% (v/v) ethanol. For the assessment of DNA contents, cell were stained with PI and monitored by FACSCalibur. Cell cycle distribution was determined with the ModFit LT program (Verity Software House Inc.). Results are derived from three independent experiments with comparable outcomes.

\section{ALDH1 activity assay}

MDA-MB 231 cells were treated with siRNAcontrol or siRNA-SMAD5 for 96 hours and ALDH1 activity was detected using the Aldeofluor assay kit (STEMCELL Technologies, Canada) according to the manufacturer's instructions. Results are derived from three independent experiments with comparable outcomes.

\section{ACKNOWLEDGMENTS AND FUNDING}

This study was supported by USAMRMC BC022276, Intramural RECDA and The Nan Sayner Awards to A.B.D., NCI CA72836 to J.L.S., the Mayo Clinic Breast Cancer Specialized Program of Research Excellence (SPORE) NIH CA116201 to J.I., M.P.G. and E.G., the Prospect Creek Foundation to E.G., the NIH Relief Fund to T.H. and the Mayo Clinic Comprehensive Cancer Center. We also wish to acknowledge the Pathology Research Core facility of the Mayo Clinic School of Medicine, for performing IHC assays and assisting us with the interpretation of the results.

\section{CONFLICTS OF INTEREST}

The authors declare that there are no competing financial interests in relation to the work described.

\section{REFERENCES}

1. Ascolani G, Occhipinti A, Lio P. Modelling circulating tumour cells for personalised survival prediction in metastatic breast cancer. PLoS Comput Biol. 2015; 11: e1004199. doi: 10.1371/journal.pcbi.1004199.

2. Opyrchal M, Salisbury JL, Iankov I, Goetz MP, McCubrey J, Gambino MW, Malatino L, Puccia G, Ingle JN, Galanis E, D'Assoro AB. Inhibition of $\mathrm{Cdk} 2$ kinase activity selectively targets the CD44(+)/CD24(-)/Low stem-like subpopulation and restores chemosensitivity of SUM149PT triple-negative breast cancer cells. Int J Oncol. 2014; 45: 1193-9. doi: 10.3892/ijo.2014.2523.

3. Alamgeer M, Ganju V, Kumar B, Fox J, Hart S, White M, Harris M, Stuckey J, Prodanovic Z, Schneider-Kolsky ME, Watkins DN. Changes in aldehyde dehydrogenase-1 expression during neoadjuvant chemotherapy predict outcome in locally advanced breast cancer. Breast Cancer Res. 2014; 16: R44. doi: 10.1186/bcr3648.

4. Li CI, Daling JR, Malone KE. Incidence of invasive breast cancer by hormone receptor status from 1992 to 1998 . J Clin Oncol. 2003; 21: 28-34. doi: 10.1200/JCO.2003.03.088.

5. Liedtke C, Bernemann C, Kiesel L, Rody A. Genomic profiling in triple-negative breast cancer. Breast Care (Basel). 2013; 8: 408-13. doi: 10.1159/000357534.

6. Qiu M, Peng Q, Jiang I, Carroll C, Han G, Rymer I, Lippincott J, Zachwieja J, Gajiwala K, Kraynov E, Thibault S, Stone D, Gao Y, et al. Specific inhibition of Notch1 signaling enhances the antitumor efficacy of chemotherapy in triple negative breast cancer through reduction of cancer stem cells. Cancer Lett. 2013; 328: 261-70. doi: 10.1016/j. canlet.2012.09.023.

7. Cortazar P, Zhang L, Untch M, Mehta K, Costantino JP, Wolmark N, Bonnefoi H, Cameron D, Gianni L, Valagussa P, Swain SM, Prowell T, Loibl S, et al. Pathological complete response and long-term clinical benefit in breast 
cancer: the CTNeoBC pooled analysis. Lancet. 2014; 384: 164-72. doi: 10.1016/S0140-6736(13)62422-8.

8. Crown J, O’Shaughnessy J, Gullo G. Emerging targeted therapies in triple-negative breast cancer. Ann Oncol. 2012; 23 Suppl 6: vi56-65. doi: 10.1093/annonc/mds196.

9. Britton KM, Eyre R, Harvey IJ, Stemke-Hale K, Browell D, Lennard TW, Meeson AP. Breast cancer, side population cells and ABCG2 expression. Cancer Lett. 2012; 323: 97 105. doi: 10.1016/j.canlet.2012.03.041.

10. Ahmad A. Pathways to breast cancer recurrence. ISRN Oncol. 2013; 2013: 290568. doi: 10.1155/2013/290568.

11. Zhang P, Sun Y, Ma L. ZEB1: at the crossroads of epithelial-mesenchymal transition, metastasis and therapy resistance. Cell Cycle. 2015; 14: 481-7. doi: 10.1080/15384101.2015.1006048.

12. Lamouille S, Xu J, Derynck R. Molecular mechanisms of epithelial-mesenchymal transition. Nat Rev Mol Cell Biol. 2014; 15: 178-96. doi: 10.1038/nrm3758.

13. Tan EJ, Olsson AK, Moustakas A. Reprogramming during epithelial to mesenchymal transition under the control of TGFbeta. Cell Adh Migr. 2015; 9: 233-46. doi: 10.4161/19336918.2014.983794.

14. Mani SA, Guo W, Liao MJ, Eaton EN, Ayyanan A, Zhou AY, Brooks M, Reinhard F, Zhang CC, Shipitsin M, Campbell LL, Polyak K, Brisken C, et al. The epithelialmesenchymal transition generates cells with properties of stem cells. Cell. 2008; 133: 704-15. doi: 10.1016/j. cell.2008.03.027.

15. Flemban A, Qualtrough D. The Potential Role of Hedgehog Signaling in the Luminal/Basal Phenotype of Breast Epithelia and in Breast Cancer Invasion and Metastasis. Cancers (Basel). 2015; 7: 1863-84. doi: 10.3390/ cancers7030866.

16. Hwang-Verslues WW, Kuo WH, Chang PH, Pan CC, Wang HH, Tsai ST, Jeng YM, Shew JY, Kung JT, Chen CH, Lee EY, Chang KJ, Lee WH. Multiple lineages of human breast cancer stem/progenitor cells identified by profiling with stem cell markers. PLoS One. 2009; 4: e8377. doi: 10.1371/ journal.pone.0008377.

17. Shipitsin M, Campbell LL, Argani P, Weremowicz S, Bloushtain-Qimron N, Yao J, Nikolskaya T, Serebryiskaya T, Beroukhim R, Hu M, Halushka MK, Sukumar S, Parker LM, et al. Molecular definition of breast tumor heterogeneity. Cancer Cell. 2007; 11: 259-73. doi: 10.1016/j.ccr.2007.01.013.

18. Horwitz KB, Dye WW, Harrell JC, Kabos P, Sartorius CA. Rare steroid receptor-negative basal-like tumorigenic cells in luminal subtype human breast cancer xenografts. Proc Natl Acad Sci U S A. 2008; 105: 5774-9. doi: 10.1073/ pnas.0706216105.

19. Lawson DA, Bhakta NR, Kessenbrock K, Prummel KD, Yu Y, Takai K, Zhou A, Eyob H, Balakrishnan S, Wang CY, Yaswen P, Goga A, Werb Z. Single-cell analysis reveals a stem-cell program in human metastatic breast cancer cells.
Nature. 2015; 526: 131-5. doi: 10.1038/nature15260.

20. Chang CJ, Yang JY, Xia W, Chen CT, Xie X, Chao CH, Woodward WA, Hsu JM, Hortobagyi GN, Hung MC. EZH2 promotes expansion of breast tumor initiating cells through activation of RAF1-beta-catenin signaling. Cancer Cell. 2011; 19: 86-100. doi: 10.1016/j.ccr.2010.10.035.

21. Chen D, Bhat-Nakshatri P, Goswami C, Badve S, Nakshatri H. ANTXR1, a stem cell-enriched functional biomarker, connects collagen signaling to cancer stem-like cells and metastasis in breast cancer. Cancer Res. 2013; 73: 5821-33. doi: 10.1158/0008-5472.CAN-13-1080.

22. Abdullah LN, Chow EK. Mechanisms of chemoresistance in cancer stem cells. Clin Transl Med. 2013; 2: 3. doi: 10.1186/2001-1326-2-3.

23. Wendt MK, Allington TM, Schiemann WP. Mechanisms of the epithelial-mesenchymal transition by TGF-beta. Future Oncol. 2009; 5: 1145-68. doi: 10.2217/fon.09.90.

24. Cammareri P, Scopelliti A, Todaro M, Eterno V, Francescangeli F, Moyer MP, Agrusa A, Dieli F, Zeuner A, Stassi G. Aurora-a is essential for the tumorigenic capacity and chemoresistance of colorectal cancer stem cells. Cancer Res. 2010; 70: 4655-65. doi: 10.1158/0008-5472.CAN-093953.

25. Chou CH, Yang NK, Liu TY, Tai SK, Hsu DS, Chen YW, Chen YJ, Chang CC, Tzeng CH, Yang MH. Chromosome instability modulated by BMI1-AURKA signaling drives progression in head and neck cancer. Cancer Res. 2013; 73 : 953-66. doi: 10.1158/0008-5472.CAN-12-2397.

26. D'Assoro AB, Liu T, Quatraro C, Amato A, Opyrchal M, Leontovich A, Ikeda Y, Ohmine S, Lingle W, Suman V, Ecsedy J, Iankov I, Di Leonardo A, et al. The mitotic kinase Aurora--a promotes distant metastases by inducing epithelial-to-mesenchymal transition in ERalpha(+) breast cancer cells. Oncogene. 2014; 33: 599-610. doi: 10.1038/ onc.2012.628.

27. Yang H, He L, Kruk P, Nicosia SV, Cheng JQ. Aurora-A induces cell survival and chemoresistance by activation of Akt through a p53-dependent manner in ovarian cancer cells. Int J Cancer. 2006; 119: 2304-12. doi: 10.1002/ ijc. 22154 .

28. Sun JM, Yang LN, Xu H, Chang B, Wang HY, Yang G. Inhibition of Aurora A promotes chemosensitivity via inducing cell cycle arrest and apoptosis in cervical cancer cells. Am J Cancer Res. 2015; 5: 1133-45.

29. Lee HH, Zhu Y, Govindasamy KM, Gopalan G. Downregulation of Aurora-A overrides estrogen-mediated growth and chemoresistance in breast cancer cells. Endocr Relat Cancer. 2008; 15: 765-75. doi: 10.1677/ERC-070213.

30. Leontovich AA, Zhang S, Quatraro C, Iankov I, Veroux PF, Gambino MW, Degnim A, McCubrey J, Ingle J, Galanis E, D'Assoro AB. Raf-1 oncogenic signaling is linked to activation of mesenchymal to epithelial transition pathway in metastatic breast cancer cells. Int J Oncol. 2012; 40: 
1858-64. doi: 10.3892/ijo.2012.1407.

31. Jin W, Wu L, Liang K, Liu B, Lu Y, Fan Z. Roles of the PI$3 \mathrm{~K}$ and MEK pathways in Ras-mediated chemoresistance in breast cancer cells. Br J Cancer. 2003; 89: 185-91. doi: 10.1038/sj.bjc.6601048.

32. D'Assoro AB, Busby R, Suino K, Delva E, AlmodovarMercado GJ, Johnson H, Folk C, Farrugia DJ, Vasile V, Stivala F, Salisbury JL. Genotoxic stress leads to centrosome amplification in breast cancer cell lines that have an inactive G1/S cell cycle checkpoint. Oncogene. 2004; 23: 4068-75. doi: 10.1038/sj.onc.1207568.

33. Maier S, Strasser S, Saiko P, Leisser C, Sasgary S, Grusch M, Madlener S, Bader Y, Hartmann J, Schott H, Mader RM, Szekeres T, Fritzer-Szekeres M, et al. Analysis of mechanisms contributing to AraC-mediated chemoresistance and re-establishment of drug sensitivity by the novel heterodinucleoside phosphate 5-FdUrd-araC. Apoptosis. 2006; 11: 427-40. doi: 10.1007/s10495-0064066-x.

34. D'Assoro AB, Busby R, Acu ID, Quatraro C, Reinholz MM, Farrugia DJ, Schroeder MA, Allen C, Stivala F, Galanis E, Salisbury JL. Impaired p53 function leads to centrosome amplification, acquired ERalpha phenotypic heterogeneity and distant metastases in breast cancer MCF7 xenografts. Oncogene. 2008; 27: 3901-11. doi: 10.1038/ onc.2008.18.

35. McCubrey JA, Abrams SL, Ligresti G, Misaghian N, Wong EW, Steelman LS, Basecke J, Troppmair J, Libra M, Nicoletti F, Molton S, McMahon M, Evangelisti C, et al. Involvement of p53 and Raf/MEK/ERK pathways in hematopoietic drug resistance. Leukemia. 2008; 22: 208090. doi: 10.1038/leu.2008.207.

36. Maire V, Nemati F, Richardson M, Vincent-Salomon A, Tesson B, Rigaill G, Gravier E, Marty-Prouvost B, De Koning L, Lang G, Gentien D, Dumont A, Barillot E, et al. Polo-like kinase 1: a potential therapeutic option in combination with conventional chemotherapy for the management of patients with triple-negative breast cancer. Cancer Res. 2013; 73: 813-23. doi: 10.1158/0008-5472. CAN-12-2633.

37. Weaver BA. How Taxol/paclitaxel kills cancer cells. Mol Biol Cell. 2014; 25: 2677-81. doi: 10.1091/mbc.E14-040916.

38. Rhodes LV, Tate CR, Segar HC, Burks HE, Phamduy TB, Hoang V, Elliott S, Gilliam D, Pounder FN, Anbalagan M, Chrisey DB, Rowan BG, Burow ME, et al. Suppression of triple-negative breast cancer metastasis by pan-DAC inhibitor panobinostat via inhibition of ZEB family of EMT master regulators. Breast Cancer Res Treat. 2014; 145: 593 604. doi: 10.1007/s10549-014-2979-6.

39. Opyrchal M, Salisbury JL, Zhang S, McCubrey J, Hawse J, Goetz MP, Lomberk GA, Haddad T, Degnim A, Lange C, Ingle JN, Galanis E, D'Assoro AB. Aurora-A mitotic kinase induces endocrine resistance through down-regulation of ERalpha expression in initially ERalpha+ breast cancer cells. PLoS One. 2014; 9: e96995. doi: 10.1371/journal. pone.0096995.

40. Luo Y, Wang X, Wang H, Xu Y, Wen Q, Fan S, Zhao R, Jiang S, Yang J, Liu Y, Li X, Xiong W, Ma J, et al. High Bak Expression Is Associated with a Favorable Prognosis in Breast Cancer and Sensitizes Breast Cancer Cells to Paclitaxel. PLoS One. 2015; 10: e0138955. doi: 10.1371/ journal.pone.0138955.

41. Chen L, Bourguignon LY. Hyaluronan-CD44 interaction promotes c-Jun signaling and miRNA21 expression leading to Bcl-2 expression and chemoresistance in breast cancer cells. Mol Cancer. 2014; 13: 52. doi: 10.1186/1476-459813-52.

42. Gatti L, Zunino F. Overview of tumor cell chemoresistance mechanisms. Methods Mol Med. 2005; 111: 127-48. doi: 10.1385/1-59259-889-7:127.

43. Martinez-Revollar G, Garay E, Martin-Tapia D, Nava P, Huerta M, Lopez-Bayghen E, Meraz-Cruz N, Segovia J, Gonzalez-Mariscal L. Heterogeneity between triple negative breast cancer cells due to differential activation of Wnt and PI3K/AKT pathways. Exp Cell Res. 2015; 339: 67-80. doi: 10.1016/j.yexcr.2015.10.006.

44. Ye X, Tam WL, Shibue T, Kaygusuz Y, Reinhardt F, Ng Eaton E, Weinberg RA. Distinct EMT programs control normal mammary stem cells and tumour-initiating cells. Nature. 2015; 525: 256-60. doi: 10.1038/nature14897.

45. Preca BT, Bajdak K, Mock K, Sundararajan V, Pfannstiel J, Maurer J, Wellner U, Hopt UT, Brummer T, Brabletz S, Brabletz T, Stemmler MP. A self-enforcing CD44s/ZEB1 feedback loop maintains EMT and stemness properties in cancer cells. Int J Cancer. 2015; 137: 2566-77. doi: 10.1002/ijc.29642.

46. Fitzgerald TL, Lertpiriyapong K, Cocco L, Martelli AM, Libra M, Candido S, Montalto G, Cervello M, Steelman L, Abrams SL, McCubrey JA. Roles of EGFR and KRAS and their downstream signaling pathways in pancreatic cancer and pancreatic cancer stem cells. Adv Biol Regul. 2015; 59: 65-81. doi: 10.1016/j.jbior.2015.06.003.

47. Davis JM, Navolanic PM, Weinstein-Oppenheimer CR, Steelman LS, Hu W, Konopleva M, Blagosklonny MV, McCubrey JA. Raf-1 and Bcl-2 induce distinct and common pathways that contribute to breast cancer drug resistance. Clin Cancer Res. 2003; 9: 1161-70.

48. Knappskog S, Berge EO, Chrisanthar R, Geisler S, Staalesen V, Leirvaag B, Yndestad S, de Faveri E, Karlsen BO, Wedge DC, Akslen LA, Lilleng PK, Lokkevik E, et al. Concomitant inactivation of the p53- and pRB- functional pathways predicts resistance to DNA damaging drugs in breast cancer in vivo. Mol Oncol. 2015; 9: 1553-64. doi: 10.1016/j.molonc.2015.04.008.

49. Katayama H, Sasai K, Kawai H, Yuan ZM, Bondaruk J, Suzuki F, Fujii S, Arlinghaus RB, Czerniak BA, Sen S. Phosphorylation by aurora kinase A induces Mdm2mediated destabilization and inhibition of p53. Nat Genet. 2004; 36: 55-62. doi: 10.1038/ng1279. 
50. Hamilton SR, Fard SF, Paiwand FF, Tolg C, Veiseh M, Wang C, McCarthy JB, Bissell MJ, Koropatnick J, Turley EA. The hyaluronan receptors CD44 and Rhamm (CD168) form complexes with ERK1,2 that sustain high basal motility in breast cancer cells. J Biol Chem. 2007; 282: 16667-80. doi: 10.1074/jbc.M702078200.

51. Daly AC, Randall RA, Hill CS. Transforming growth factor beta-induced Smad1/5 phosphorylation in epithelial cells is mediated by novel receptor complexes and is essential for anchorage-independent growth. Mol Cell Biol. 2008; 28: 6889-902. doi: 10.1128/MCB.01192-08.

52. ten Dijke P, Hill CS. New insights into TGF-beta-Smad signalling. Trends Biochem Sci. 2004; 29: 265-73. doi: 10.1016/j.tibs.2004.03.008. 